\title{
Inteligência coletiva: comunicação, capitalismo cognitivo e micropolítica*
}

\begin{abstract}
RESUMO
Os processos de colaboração estão presentes por toda a parte em nossa sociedade. Na esfera da comunicação as redes digitais popularizaram as ações colaborativas, sendo o fenômeno das comunidades virtuais seu fato mais marcante. Já no âmbito do trabalho imaterial, vamos encontrar um forte apelo às redes de colaboração, que tornou-se um refrão ecoando por todo o mundo organizacional. Há mais de uma década o conceito de inteligência coletiva passou a ser sinônimo dessa noção de colaboração, tanto na comunicação quanto no campo do trabalho. Mas será que o conceito se esgota aí? O presente artigo resulta de uma reflexão sobre essas dimensões do conceito de inteligência coletiva e da abertura a uma nova dimensão, a micropolítica, onde ele passa a ser entendido como resistência aos processos de alienação do capitalismo cognitivo.
\end{abstract}

\section{PALAVRAS-CHAVE}

inteligência coletiva

capitalismo cognitivo

micropolítica

\section{ABSTRACT \\ Collaborative processes are present in our society everywhere. Digital networks throughout the communication field popularized collaborative actions, virtual communities being its more relevant fact. On the other hand, through the immaterial labour, we will find a strong plea for collaborative networks that became a kind of mantra within the organizational world. Since a decade ago the concept of collective intelligence has been seen as a synonym of this collaboration understanding, either in communicational or labouring field. But is it the only meaning of the concept of collective intelligence? The present article is a reflection about the dimensions of the concept of collective intelligence and its opening to another dimension, the micro politics, where it is understanding as a resistance to alienation process of cognitive capitalism.}

\section{KEY WORDS}

collective Intelligence

cognitive Capitalism

micropolitics

\section{Rogério da Costa}

Professor do Programa de Pós-Graduação em Comunicação e Semiótica da PUCSP/SP/BR

rogcosta@pucsp.br

\section{A comunicação}

É fato que a noção de rede social vem sendo empregada em larga escala para designar os fenômenos de cooperação ativa ou de simples colaboração via Internet. Ela ressoa então, no espaço da cibercultura, com as noções de comunidade virtual e de comunidade de prática $\mathbf{1}^{1}$. Esse caso específico contribuiu decisivamente para uma nova percepção de rede social, mais complexa do que aquela que propunham Mark Granovetter (1974) e Barry Wellman (1988) nos anos de 1970 e 1980, e que foi se consolidando juntamente com a expansão da Web. Tal percepção, sem ser exclusiva do universo virtual, ganha nele um sentido que traduz melhor do que em qualquer outro lugar o tipo de sociedade pós-industrial que estamos construindo. É nele que a rede social passa a ser vista não apenas como algo a ser constatado, detectado, mapeado, analisado, enfim, como um dado; mas igualmente, e sobretudo, como um fazer, um construir. Fazer rede. Eis o que parece introduzir uma diferença que deve repercutir nos diversos estudos sobre a dinâmica de formação dos laços sociais. Como fazer rede? Como construir uma comunidade virtual ou uma comunidade de prática? Como ampliar a sinergia entre indivíduos em graus e escalas diferenciadas (Kim, 2000; Figallo, 1998; Preece, 2000)? Tais questões tornam pertinente a correlação entre inteligência coletiva e redes sociais do ponto de vista da comunicação e dos meios de comunicação. Isso porque, como o próprio conceito indica de uma forma intuitiva, inteligência coletiva se refere à circulação e multiplicação de idéias nos coletivos. Portanto, se desejamos pôr as idéias em movimento, devemos buscar os meios para colocar os indivíduos em relação, meios que possam facilitar a sinergia entre as pessoas.

Mas o problema, colocado dessa forma, corre o risco de se ver reduzido a uma busca por instrumentos de comunicação; e em alguns casos, tratando-se da Internet, é isso que se verifica. Todos sabemos, no entanto, das enormes dificuldades por que passam projetos envolvendo grupos e comunidades. A perda de sinergia entre as pessoas; as resistências na adoção de novas idéias, comportamentos, compromissos; o desvio na definição de metas; os equívocos na coordenação dos atores (elemento político) são apenas alguns dentre os vários desafios enfrentados pelos promotores de projetos coletivos (Mendes, 2007). No campo da comunicação, esses desafios estão ligados ao uso intenso das tecnologias da Web, que ao mesmo tempo em que permitem uma ampla interação entre os seus mais diversos atores, também decepcionam, de forma específica, aqueles que pretendem explorá-las do ponto de vista da ampliação da sinergia entre participantes de projetos sociais. Muitos 
promotores têm dispendido grande energia na busca por meios de comunicação que possibilitem uma melhor interação entre esses participantes via Internet. De forma geral, eles têm concluído que seus problemas vão além da escolha de ferramentas de tecnologia de comunicação.

Projetos nas áreas de educação e saúde, por exemplo, ressentem-se de recursos conceituais e metodológicos que possam orientá-los sobre a melhor maneira de colocar seu público num plano de comunicação efetiva ou comprometida com os desafios e problemas em que estão implicados. São projetos que dependem, de alguma forma, do sucesso dessa interação virtual para alavancar ações específicas no âmbito presencial. No nível do ensino fundamental, por exemplo, um dos maiores desafios é não apenas prover as escolas com recursos informáticos, mas ainda conquistar um novo patamar nos conceitos de ensino-aprendizagem que possa incluir efetivamente o uso do espaço virtual sem preconceitos, temores ou desqualificações. Também no campo da saúde, avançou-se muito na oferta de informações e serviços, mas pouco na formação de redes cooperativas que atuem na disseminação de boas práticas ou na construção conjunta de novas estratégias que impliquem os diversos usuários do sistema, como pacientes, médicos, farmacêuticos, pesquisadores, empresas seguradoras, governo etc (Teixeira, 2005; Mendes, 2007).

\section{Economia Cognitiva: Trabalho imaterial e Capital social}

Segue-se, então, um segundo momento em nossa proposta de interrelação da inteligência coletiva com o fazer redes sociais. Está claro para nós que a dinâmica da comunicação na formação de redes sociais alimenta-se, fundamentalmente, da expansão do trabalho imaterial. Tal como definido por Antonio Negri e Michael Hardt (2005), o trabalho imaterial envolve três dimensões essenciais: a cognição (conhecimento), a comunicação (informação) e o afeto (cuidado). Dessa forma, o que vem dar sentido ao fazer rede é tanto a busca e oferta de informações, a construção e partilha de conhecimentos quanto a troca afetiva. Na sociedade pós-industrial, que muitos chamam sociedade da informação ou sociedade do conhecimento (Drucker, 1993), as riquezas imateriais tornaram-se o foco privilegiado da produção de valor. Assim, a ação em rede ou ação coletiva passa a ser sinônimo de ação colaborativa ou cooperativa voltada para a produção de valores imateriais que, por sua vez, sobrecodificam os valores materiais ou bens de consumo. É neste sentido que o fazer rede passa a ser objeto da economia política, uma vez que a produção de valor econômico não está dissociada da forma como os indivíduos interagem ao atuarem na partilha de conhecimentos e informações através de suas redes sociais.

Deve-se assinalar que, já em 1979, Michel Foucault (2004), em seu curso sobre o nascimento da biopolítica, mostrava como o neoliberalismo defendia uma nova maneira de analisar a natureza do trabalho, apontando para essa verdadeira mutação que passou a ver o indiví- duo como detentor de capital humano, já que possuidor de conhecimentos e competências. Tem-se nas análises de Foucault um dos primeiros momentos de percepção do que chamamos hoje de capitalismo cognitivo ou economia do imaterial e, também, uma antecipação dos estudos sobre gestão do conhecimento, que só emergiram no início da década de 1990 (Senge, 1990; Drucker, 1993; Nonaka\& Takeuchi, 1995). Essa noção de capital humano, que se consolida a partir dos estudos de Gary Becker (1964), revela o interesse das análises econômicas na compreensão das ações e relações dos indivíduos, análises até então desconhecidas da economia clássica. Mas é interessante notar que, simultaneamente aos estudos de Foucault, Mark Granovetter (1974) propunha um outro ângulo de análise dessas mesmas transformações, pois partia diretamente da idéia de redes sociais e da forma como os indivíduos se associavam tanto social como economicamente. Granovetter está convencido de que a riqueza são as conexões, o networking dos indivíduos. Ele faz um esforço enorme para mostrar que as ações econômicas estão incrustadas na dinâmica das redes sociais, o que significa afirmar que a nova economia deve levar em conta o papel do capital social. Então, desde o final da década de 1970 já é possível constatar a existência de estudos sobre a formação de redes sociais e sua relação com a produção econômica. O conceito de capital social (Bourdieu, 1980), posterior ao de capital humano, só faz aprofundar o alcance das análises econômicas que passam a incluir as formas de interrelação dos indivíduos como fonte de valor.

\section{Evidencia-se um conjunto de ações que transpassa os setores produtivos e que se apóia no estímulo à cooperação e colaboração dos indivíduos através da formação de redes de trabalho, sejam elas locais ov virtuais.}

Nos anos de 1980, Granovetter (1985) e Barry Wellman (1988) aprofundam suas análises estruturais de redes sociais. Esses estudos mostraram o quanto é importante reconhecer que as estruturas sociais podem ser representadas como redes - um conjunto de nós e de laços que descrevem suas interconexões. Nesse caso, os nós podem representar não apenas indivíduos, mas igualmente grupos, corporações, domicílios, nações ou outras coletividades. 
Os laços são usados para representar fluxos de recursos, relações de amizade simétricas, transferências ou relações estruturadas entre nós. Barry Wellman e Stephen Berkowitz (1988) analisam arranjos ordenados de relações que ocorrem nas trocas entre membros de sistemas sociais, mapeiam essas estruturas, descrevem seus padrões e procuram descobrir seus efeitos no comportamento dos indivíduos membros dessas estruturas - sejam pessoas, grupos ou organizações.

Mas essa forma de abordagem de redes sociais, que busca por padrões de comportamento do coletivo, permanece em um nível ainda insuficiente quando se trata de compreender a dinâmica de implicação dos indivíduos em processos coletivos que envolvem cooperação em ações com propósitos definidos.

Por isso, para além desse método de análise fundamentalmente estrutural, fez-se necessária uma abordagem qualitativa das redes. Nesse sentido, o conceito de capital social foi utilizado por diversos teóricos (Coleman, 1990; Putnam, 1993; Lin, 2001 e 2005; Burt, 2000) para sustentar suas análises sobre a construção do laço social e, portanto, sobre a formação de redes sociais. Cabe lembrar que as relações sociais passam a ser percebidas como um "capital", justamente, quando o processo de crescimento econômico passa a ser determinado não apenas pelo capital natural (recursos naturais), pelo capital produzido (infra-estrutura e bens de consumo) ou ainda pelo capital financeiro. Além desses, seria ainda preciso determinar o modo como os atores econômicos interagem e se organizam para gerar crescimento e desenvolvimento. A compreensão dessas interações passa a ser considerada como riqueza a ser explorada, capitalizada. Como assinalam Woolcock e Narayan (2000):

Um dos conceitos de capital social, que encontramos nos sociólogos R. Burt, N. Lin e A. Portes, refere-se aos recursos - como, por exemplo, informações, idéias, apoios - que os indivíduos são capazes de procurar em virtude de suas relações com outras pessoas. Esses recursos ('capital') são 'sociais' na medida em que são acessíveis somente dentro e por meio dessas relações, contrariamente ao capital físico (ferramentas, tecnologia) e humano (educação, habilidades), por exemplo, que são, essencialmente, propriedades dos indivíduos. A estrutura de uma determinada rede - quem se relaciona com quem, com que freqüência, e em que termos - tem, assim, um papel fundamental no fluxo de recursos através daquela rede. Aqueles que ocupam posições estratégicas no interior da rede, especialmente aqueles cujas ligações percorrem vários grupos, potencialmente têm mais recursos do que seus pares, precisamente porque sua posição no interior da rede lhes proporciona maior acesso a mais e melhores recursos ${ }^{2}$.

Há uma relação neste caso estreita entre capital social e sistema produtivo e financeiro. Alguns chamam a isso de neocapitalismo, que inclui o capital humano, cultural e social (Lin, 2001). Cabe lembrar que desde o início dos anos 1990, na mesma década em que os estudos sobre o capital social se consolidaram, as primeiras análises sobre gestão do conhecimento floresciam e já apontavam para a importância dos conhecimentos e informações como ativos intangíveis das empresas, ressaltando que o estímulo à partilha e troca desses ativos, entre os colaboradores, significava a ampliação do capital intelectual das organizações (Nonaka, Takeuchi, Drucker, Senge). Lembremos, igualmente, que um dos primeiros estudos de uma agência governamental sobre esse tema data de 1996, e encontra-se no relatório da OCDE intitulado "The knowledge-based economy", coordenado por D. Foray e B. Lundvall (1996).

\section{Mas para investigar esse aspecto da inteligência coletiva, seu elemento de resistência política, devemos aprofundar nossa percepção do trabalho imaterial e do quanto ele opera em diferentes dimensões da subjetividade dos indivíduos.}

Atualmente, é difícil encontrar um setor econômico que não faça uso da noção de rede social como elemento importante para seu crescimento. Isso porque o capital de conhecimento e informação passou a estruturar as iniciativas econômicas nas suas mais diversas instâncias. Portanto, fazer rede, atualmente, é sinônimo de produção de valor econômico pela atividade colaborativa das inteligências dos indivíduos. E essa produção, é preciso assinalar, não está restrita ao universo das organizações econômicas, mas estende-se sobre toda a sociedade, na medida em que toda atividade humana pode ser vista como produtora de alguma forma de riqueza imaterial.

\footnotetext{
A micropolítica: o campo de sustentabilidade subjetiva

Um terceiro momento deve, portanto, intervir na relação entre o fazer rede e o tornar-se uma inteligência coletiva, agora no sentido político do termo. Dado que toda atividade que produz conhecimento e informação é produtora de riqueza, a conversão dessa riqueza em valor econômicoé o que caracteriza fundamentalmente o atual capitalismo cognitivo. Como assinala Yann Boutang (2007a), “o recurso do qual o capitalismo procura se tornar mestre atualmente é a inteligência coletiva, a criatividade difundida no conjunto da população". O capitalismo cog-
} 
nitivo depende basicamente das atividades de cooperação intelectual dos indivíduos, tanto do ponto de vista da comunicação quanto da produção de conhecimento. E essa cooperação se traduz hoje como um fazer rede generalizado. Evidencia-se, portanto, um conjunto de ações que transpassa os setores produtivos e que se apóia no estímulo à cooperação e colaboração dos indivíduos através da formação de redes de trabalho, sejam elas locais ou virtuais. Então, por detrás do suposto valor positivo da "cooperação", nos defrontamos com práticas que visam extrair mais valia dos "produtos" dessa atividade cooperativa. Nesse cenário, preferimos entender que a inteligência coletiva é antes de tudo uma ação de resistência a essas novas formas de alienação do trabalho, mais do que o motor do capitalismo cognitivo.

\section{Situações de engajamento} afetivo em certas profissões são fator necessário para o bom

\section{desempenho do ponto de vista do empregador ou do sistema.}

Mas para investigar esse aspecto da inteligência coletiva, seu elemento de resistência política, devemos aprofundar nossa percepção do trabalho imaterial e do quanto ele opera em diferentes dimensões da subjetividade dos indivíduos. Isso significa analisar a forma como a subjetividade é convocada, implicada nos processos de trabalho com o conhecimento, a comunicação e os afetos. As pesquisas mais recentes de teóricos como Toni Negri (2001), Michael Hardt (2003), Maurizio Lazzaratto (2004 e 2007), Yann Boutang (2007a e 2007b) e Pélbart (2003), por exemplo, não deixam de apontar para os elementos de captura e alienação implícitos nessas novas formas de trabalho, que convocam os indivíduos no extremo de sua capacidade de pensar, imaginar, comunicar e sentir.

No campo do trabalho imaterial, há uma espécie de aprofundamento no uso dos "recursos" da subjetividade, algo como a exploração das riquezas subjetivas que se constitui como nova fronteira do sistema de produção capitalístico. Não mais apenas escavar da terra seus recursos naturais, nem tampouco se contentar em extrair energia do corpo humano, mas além disso e sobretudo escavar na subjetividade e extrair os recursos psíquicos que fazem a produção econômica funcionar. O incentivo desmesurado que assistimos hoje para a formação de redes humanas associativas acaba servindo a propósitos que ultrapassam em muito a suposta positividade da colaboração. Por outro lado, a inteligência coletiva emerge da mesma atuação em rede que deve favorecer a partilha de recursos e a construção de um comum que pode beneficiar a todos. Há portanto aqui uma tensão que não se resolve facilmente, pois a mesma formação de redes sociais tanto pode servir ao empoderamento dos indivíduos quanto alimentar seu processo de alienação subjetiva. Estamos bem longe da clareza de uma dicotomia.

Essa ambigüidade das redes sociais nos leva a indagar sobre as condições de sustentabilidade subjetiva do trabalho imaterial. Está claro que a promoção de redes humanas serve à expansão das mais diversas atividades em todos os setores da economia. Mas o que não fica claro é o quanto de energia subjetiva tem sido empregada para sustentar as usinas de produção de conhecimentos, informação e afetividade. A exploração dos recursos subjetivos parece ilimitada, e talvez realmente o seja. A pergunta é se ela não precisaria se dar a ritmos sustentáveis.

Tem-nos parecido que a dinâmica do trabalho imaterial se abre a um ritmo de exploração bem distinto do trabalho industrial. A fadiga do corpo no regime de trabalho industrial, e também agrícola, deve-se fundamentalmente aos processos de exploração da condição física dos trabalhadores. O corpo, nesse caso, é o limite da ação de exploração. A situação de ruína do corpo significa sua parada, seu limite. Todos podemos sentir que há um limite para a atuação do corpo, que existe um ponto de parada, de não funcionamento do sistema. O corpo revela-se finito. Esse fato reforça a percepção de que no mundo industrial, um trabalhador sempre pode ser substituído por outro, como uma peça quebrada que se troca.

Hoje, no entanto, estamos atravessando um período marcado pela extrema importância das atividades cognitivas, de comunicação e afetivas, que não parecem estabelecer os mesmos limites de exploração que a condição física do corpo claramente impunha.

Quando nos dobramos sobre a dimensão de trabalho imaterial, que convoca sobretudo um esforço de outra natureza, um esforço de memória, de imaginação, de associação de idéias, de comunicação constante, de dedicação afetiva, nos perguntamos: como avaliar os limites? Até onde podemos ir ou devemos ir? Essa questão, que aparece com tanta clareza no exemplo dos trabalhadores da saúde e da educação (Teixeira, 2005; Mendes, 2007), nos faz pensar nas novas formas de exploração do trabalho, mas igualmente nas novas maneiras de resistência, que não passam exclusivamente pela greve que tem como força justamente a imobilização dos corpos.

É fato que a mente não pode parar e nem a imaginação cessar ou apaziguar-se. A greve do pensamento e da imaginação com certeza será algo de outra natureza que as greves que conhecemos. E se a mente não pode deixar de funcionar, isso pode significar que ela pode trabalhar continuamente... ou que não temos a mesma noção dos limites que construímos em relação ao nosso corpo. Aqui reencontramos uma interessante referência feita por De- 
leuze (1986) em seu texto sobre Foucault, onde ele nos fala do finito-ilimitado, referindo-se à finitude do corpo e ao ilimitado da linguagem, das combinações genéticas e das máquinas cibernéticas e de informática. Mas deveríamos dizer, de forma um pouco diferente, que se o corpo é finito, é o trabalho de exploração da subjetividade, por outro lado, que é ilimitado.

A força do capitalismo atual reside exatamente neste ponto: estamos agora sempre trabalhando, porque estamos sempre refletindo, imaginando, discutindo em qualquer lugar e qualquer situação (Espere! Tive uma idéia!). Mas isso não exclui o fato de que possamos adoecer dentro dessas condições, e que realmente já não estejamos adoecendo de trabalho imaterial. Mas que nova espécie de fadiga será essa? Que novo cansaço toma conta do nosso corpo e da nossa subjetividade? Depressão, angústia, stress? E tudo isso remete a que causa ou efeito sobre nós?

\section{Sobre o "uso de si" e o "abuso de si"}

Nossa hipótese é de que há uma diferença entre o "uso de si" e a "construção de si" nas novas formas de trabalho. Uma diferença entre o uso que é feito do self, das situações de expropriação da potência do si, de alienação de nossa subjetividade e, por outro lado, das situações em que construímos ativamente nosso self, construção eminentemente coletiva, social, baseada na integração de afetos, que opera por composição e socialização da força de existir de cada um.

Em relação ao primeiro aspecto, podemos dizer que há uma forma de engajamento do trabalhador que precipita sua força subjetiva numa situação de exploração do si. Sabe-se, por exemplo, que situações de engajamento afetivo em certas profissões são fator necessário para o bom desempenho do ponto de vista do empregador ou do sistema. O problema é que "atender bem", "acolher", "ser cordial", entre outros aspectos, implica uma mobilização da subjetividade que vai além dos conhecimentos e competências de qualquer profissional, daquilo que supostamente "se aprende" no sistema de formação clássico. Quando se ouve "você deve acolher", "deve atender bem, ser cordial", nunca se pergunta se o trabalhador estaria em condições de responder a essa demanda. Espera-se simplesmente que ele incorpore essa necessidade como um "eu devo" e não como um "eu posso" ou "isso está ao alcance de minhas forças". É a construção do trabalhador moral. O apelo à consciência moral aqui é claro, e vem rodeado de todas as ameaças implícitas no sistema tradicional (perda de emprego, de salário, de posto etc). O fato é que esse tipo de demanda visa obter um certo "comportamento" daquele que trabalha. Assim como nas situações em que é necessário um certo conhecimento, habilidade ou competência para exercer uma função, e que portanto em teoria bastaria "aprender" para exercê-la, aqui também se supõe que basta exercer aquilo que supostamente todos já sabem de algu- ma maneira: atender bem, cuidar, ser atencioso. Trata-se de um pressuposto implícito ao novo sistema ${ }^{3}$.

Há vários aspectos que se entrecruzam nesse momento. Um deles é o uso "consciente" de si. Um indivíduo se empenha tendo como foco o poder, o reconhecimento ou a remuneração exclusivamente. É uma forma de engajamento no mundo, um investimento do olhar centrado em benefícios que se articulam com a sustentação individual. Daí surgem as preocupações com a partilha de conhecimentos e informações, sentindo-se como ameaça à sua posição e interesses os processos de colaboração. "Alguém pode fazer uso do que sei para avançar sobre meu território". Neste caso, o trabalho de cooperação é conduzido dentro de uma lógica de apropriação de resultados, onde se procura diferenciar o que pertence a si, o que se deve reter como próprio. Além disso, há aqui também um processo inverso de "uso do outro", que se manifesta exatamente dentro das atividades de colaboração e cooperação em rede que tanto são incentivados. Indivíduos com foco no poder, dinheiro ou prestígio, exclusivamente, podem facilmente se apropriar de processos colaborativos, fazendo uso do outro em seu benefício próprio. Isso não significa que estejam menos alienados do ponto de vista de sua força de existir.

\section{0 exemplo do telefone celular é muito significativo dessa prestatividade contínua: eterna disponibilidade para cuidar, atender, ser atencioso.}

Outro aspecto é o "uso de si" como seqüestro da potência subjetiva. Neste caso, aponta-se para a situação de captura da subjetividade, sobretudo em processos de trabalho afetivo, onde um "devo fazer" se instala como pólo atrator. Aqui, o investimento moral se sobrepõe às forças subjetivas, canalizando o trabalho para um "sempre além" do que se pode, de suas capacidades reais, para um ponto de esgarçamento subjetivo. Não se duvida que seja sempre possível atender melhor, cuidar melhor, ser mais atencioso etc. Mas igualmente, também na produção de conhecimentos e nos processos de comunicação é possível verificar um fenômeno semelhante, pois sempre se pode conhecer mais (educação continuada) ou comunicar mais e melhor (somos todos jornalistas...). Enfim, sempre é possível colaborar com mais conhecimentos, cooperar mais com os parceiros. Esse excesso, esse além do limar de sustentação subjetiva configura um uso de si como um "abuso de si". Sempre se está sujeito a uma cobrança para além do ponto, seja pelo sistema, pelo empregador, pelo "cliente" ou, o que é 
mais comum, por si mesmo. A resposta a essa cobrança chama-se, curiosamente, "dedicação ao trabalho". Trata-se de uma espécie de prontidão afetiva, de um estado de alerta afetivo permanente em que nos encontramos. $\mathrm{O}$ exemplo do telefone celular é muito significativo dessa prestatividade contínua: eterna disponibilidade para cuidar, atender, ser atencioso. Muitas são as situações em que o trabalhador simplesmente não tem condições para sustentar um tal processo de esgarçamento. Como resultado, os índices de depressão, angústia e stress de que são vítimas inúmeros profissionais, sobretudo aqueles ligados à educação, à saúde e à comunicação. Por fim, como avaliar a inteligência coletiva senão como resistência a essa alienação, mas dentro da própria dinâmica de colaboração em rede.

\section{Conclusão: a construção de si está na relação}

O que dizer então dessa outra dimensão que aponta para a "construção de si"? Um dos pontos ressaltados pelos recentes trabalhos de Toni Negri (2001 e 2005) diz respeito ao investimento no trabalho como atividade vital, produtora de riquezas e valor. Não há como distinguir os seres humanos de suas atividades em todas as ordens (familiar, cuidado de si, cuidado do outro, produção de bens materiais e imateriais). Isso significa que quando se trabalha, em qualquer dimensão, sempre se está implicado com sua existência de fato, concretamente. Tanto que o "uso de si", seja de forma consciente, seja alienada, não nos coloca fora da ordem do investimento de potência real, onde a existência está realmente implicada. Nós nos tornamos o que estamos fazendo, nos precipitamos imperceptivelmente em nossas atividades, nos deparamos absortos em pensamentos e sentimentos inteiramente focados nas tarefas que executamos. Do ponto de vista do trabalho imaterial, que é basicamente um trabalho de pensamento, afetos e comunicação, esse investimento é fundamentalmente da ordem da subjetividade. Não significa que o corpo não esteja ali, mas que sua dimensão motora é secundária em relação ao exercício da memória, da imaginação, da convocação afetiva e da manifestação dos sentimentos. Na verdade, este é o caso em que, ao contrário da presença autômata do corpo do operário industrial do século XIX e até meados do século XX, o corpo do trabalhador do imaterial está realmente ali, com sua potência inteiramente implicada.

Nossa hipótese é a de que a "construção de si", em qualquer ordem de atividade, necessita de um investimento do olhar diferente da objetificação encontrada no "uso de si". Agora, não se trata mais de olhar para o seu cargo, sua função, sua promoção ou o quanto de poder se pode obter em relação aos outros. Trata-se fundamentalmente de um olhar voltado para a "relação" que nasce do lugar que se ocupa, mas que é provocada pela existência do outro. De fato, cargos e funções revelam uma forma de organização que procura prescindir da singularidade das relações, porque pretende de fato orquestrá-las. No entanto, quando tratamos de atividades que só podem acontecer nas relações (como é o caso na saúde, na educação, no direito, no meio-ambiente, nos trabalhos do terceiro setor em geral etc.), somos forçados a reconhecer que a implicação da subjetividade não só é necessária como também está sujeita a ordens de composição com o outro que a alimentam, fortalecem, provocando reações e precipitações que não estão previstos no script da atividade ${ }^{4}$. Mas pode ser que nesse momento, paradoxalmente, o trabalhador das relações se veja só, que possa contar apenas com seus próprios recursos de conhecimento, sensibilidade, memória ou afeto para "fazer funcionar a relação" dos outros. Mas a "relação" não é uma máquina que se faz funcionar, ou um processo burocrático ao qual se dá andamento, ou mesmo um atendimento "padrão" que se executa. Para uma relação "andar", é preciso estar lá onde ela acontece, é preciso se perceber existindo na relação. E é aqui que pode-se falar em "construção de si".

\section{0 trabalho afetivo é tanto 0 lugar dessa precipitação que chamamos de "abuso de si", quanto a chance de emergência da inteligência coletiva como resistência às ações de alienação e do imperativo da colaboração.}

Mas no ponto em que estamos, o que seria mais precisamente a inteligência coletiva? Inteligência coletiva, na dimensão da micropolítica, seria uma percepção que emerge em cada indivíduo quando este se dá conta de que, em suas ações de trabalho e mesmo no dia-a-dia, existe interdependência em relação às ações de outros indivíduos. O que permite a emergência da inteligência coletiva é o fato de se ver dentro de uma rede de relações onde se depende da composição com outros indivíduos e que, simultaneamente, entende-se que eles também dependem de sua participação.

Essa inteligência é quase entendida aqui como uma consciência, como um acordar. De fato, quando referíamos a inteligência coletiva aos processos dos meios de comunicação, intuitivamente isso remetia à circulação de idéias, de conhecimentos e informações. Mas isso tanto pode ser um simples processo superficial de trocas entre desconhecidos ou mesmo pessoas pouco conhecidas (e que é a grande característica do zumbido planetário da Internet), quanto alimentar uma rede com forte interdependência, como no caso de muitas comunidades de prática e dos movimentos de ativismo via Web. Da mesma forma, no campo do trabalho imaterial, a 
inteligência coletiva tanto pode se resumir às atividades colaborativas intermitentes dos grupos de projetos em organizações, quanto revelar a interdependência de atividades transsetoriais, como é o caso, por exemplo, da educação, justiça e saúde.

No entanto, ambas as dimensões são passíveis de uma leitura a partir de padrões sistêmicos, onde inteligência coletiva torna-se algo que só se percebe quando se observa o desenrolar desses padrões ao longo do tempo. Então essa inteligência seria inteiramente inconsciente e próxima daquela dos insetos. O que estamos ressaltando aqui é a possibilidade de uma leitura ativa da inteligência coletiva. É essa leitura que pode fazer referência não apenas à consciência que o indivíduo tem de si mesmo, mas à consciência no indivíduo de sua rede de sustentação subjetiva.

Ou seja, consciência da interdependência não apenas em sua forma objetiva (dependo do trabalho de alguém), mas igualmente subjetiva (dependo da estima, do cuidado de outro). É esse conceito de inteligência coletiva que funciona como resistência, como promotora dos limites subjetivos, que sustenta nossos investimentos no mundo do trabalho pessoal. Inteligência coletiva como estratégia que busca dar limites às atividades afetivas, para que o "uso de si" não se transforme em "abuso de si".

Finalmente, entendemos que a sustentação dessa interdependência está na construção da confiança, de integração de simpatias, de estima, de respeito e que a socialização dos afetos é a chave da construção e da sustentação do meio em que se vive e se trabalha (Costa, 2005). Mas o que promove essa integração? Nossa compreensão é que o trabalho afetivo é o principal vetor que permite uma tal construção. Ele produz redes sociais, formas diversas de comunidades. O trabalho afetivo é tanto o lugar dessa precipitação que chamamos de "abuso de si", quanto a chance de emergência da inteligência coletiva como resistência às ações de alienação e do imperativo da colaboração. O objetivo principal dessa resistência é mudar o sentido a partir do qual se promove a formação de redes sociais wFAmEcos

\section{NOTAS}

* Texto apresentado no II Seminário da ABCiber. Novembro 2008.

1 O texto inaugural sobre esse assunto é sem dúvida "A Comunidade Virtual" de Howard Rheingold, de 1993. Ao final da década de 1990 e no início dos anos 2000 muitos autores lançaram livros propondo como construir comunidades virtuais. Etienne Wenger, um educador suíço, obteve sucesso em 2002 difundindo técnicas para a promoção de comunidades de prática.

2 Cf. WOOLCOCK, M.; NARAYAN, D. Social Capital: Implications for Development Theory, Research, and Policy. In: The World Bank Research Observer, v.15, n.2, pp. 225-249, 2000.

3 Essa questão do "uso de si" no trabalho é muitas vezes abordada numa dimensão que é construída em paralelo com a da remuneração do trabalhador. Tratase de procurar outras fontes de engajamento do interesse dos indivíduos, de forma a garantir que eles se empenhem no exercício dos valores subjetivos. É assim que os programas de alinhamento com a missão e visão da empresa ou sistema são propostos, incentivos além do financeiro são oferecidos e compromissos com a marca são ressaltados, de forma a assegurar uma implicação da subjetividade do trabalhador.

4 Sobre esses aspectos veja-se, especialmente, Teixeira (2005) e Mendes (2007).

\section{REFERÊNCIAS}

BECKER, G. Investiment in Human Capital: A theoretical and empirical analysis with special reference to education. Nova York: National Bureau of Economic Research, 1964.

BOURDIEU, P. Le capital social: notes provisoires. In: Actes de la Recherche en Sciences Sociales 3: 2-3, 1980.

BOUTANG, Y. Le capitalisme Cognitif: la nouvelle Grande Transformation. Paris: Amsterdam, 2007a.

(org). Politiques des Multitudes. Democratie, Intelligence Collective e Puissance de la vie à l'heure du capitalisme cognitif. Paris: Amsterdam, 2007b.

BURT, R. The Network Structure of Social Capital. In: SUTTON, R.; STAWS, B. (eds) Research in Organizational Behavior Greenwich, CT : JAI Press, 2000.

COLEMAN, J. Foundations of Social Theory. Cambridge, Mass: Harvard University Press, 1990.

COSTA, R. Por um Novo Conceito de Comunidade: redes sociais, comunidades pessoais, inteligência coletiva. In: Revista Interface - Comunicação, Saúde, Educação. São Paulo: Unesp, v.9, n.17, mar/ago, pp. 235-248, 2005.

DELEUZE, G. Foucault. Paris: Les Editions de Minuit, 1986.

DRUCKER, P. The Post-Capitalist Society. New York: HarperBusiness, 1993.

FIGALLO, C. Hosting Web Communities: building relationships, increasing customer loyalty, and maintaining a competitive edge. Nova Iorque: Wiley Computer Publishing, 1998. 
FORAY, D.; LUNDVALL, B. The knowledge-based economy. Paris: OCDE, 1996.

FOUCAULT, M. Naissance de la Biopolitique. Paris: Gallimard/Seuil, 2004.

GRANOVETTER, M. Getting a Job: a study of contacts and careers. Chicago: University of Chicago Press, 1974._. Economic Action and Social Structure: The Problem of Embeddedness. In: American Journal of Sociology, v.91, n.3, pp. 481-510, 1985.

HARDT, M. O trabalho afetivo. In: COSTA, R. \& PÉLBART, P. (orgs). O Reencantamento do Concreto. São Paulo: Hucitec, 2003.

KIM, A.J. Community Building on the Web. Berkeley: Peachpit Press, 2000.

LAZZARATO, M. Les revolutions du capitalisme. Paris: Les Empêcheurs de Penser en Rond, 2004.

. Biopolitique/Bioéconomie. In: BOUTANG, Y. (org). Politiques des Multitudes. Democratie, Intelligence Collective e Puissance de la vie à l'heure du capitalisme cognitif. Paris: Amsterdam, 2007.

LIN, N. Social Capital: A Theory of Social Structure and Action. New York: Cambridge University Press, 2001

LIN, N.; COOK, K.; BURT, R. Social Capital: theory and research. Londres: Aldine Transaction, 2005.

MENDES, V. L. F. Uma Clínica no Coletivo: experimentações no Programa de Saúde da Família. São Paulo: Hucitec, 2007.

NEGRI, A.; HARDT, M. Multidão. São Paulo: Record, 2005.

NEGRI, A. Exílio. São Paulo: Iluminuras, 2001.

NONAKA, I.; TAKEUCHI, H. The Knowledge-Creating Company. New York: Oxford University Press, 1995.

PÉLBART, P. P. Vida Capital: ensaios de biopolitica. São Paulo: Iluminuras, 2003.

PREECE, J. Online Communities. Chichester: John Wiley \&Sons, 2000.

PUTNAM, R.; LEONARDI, R.; NANETTI, R. Making Democracy Work: Civic Traditions in Modern Italy. Prince- ton: Princeton University Press, 1993.

RHEINGOLD, H. A Comunidade Virtual. Lisboa: Gradiva, 1996.

SENGE, P. The Fifth Discipline: The art and practice of the learning organization. New York: Doubleday, 1990.

TEIXEIRA, Ricardo. O desempenho de um serviço de atenção primária à saúde na perspectiva da inteligência coletiva. In: Revista Interface - Comunicação, Saúde, Educação. São Paulo: Unesp, v.9, n.17, mar/ ago, pp. 219-234, 2005.

WELLMAN, B \& BERKOWITZ, S. D. Social structures: $a$ network approach. New York: Cambridge University Press, 1988.

WOOLCOCK, M.; NARAYAN, D. Social Capital: Implications for Development Theory, Research, and Policy. In: The World Bank Research Observer, v.15, n.2, pp. 225-249, 2000.

ZOLA, E. O Germinal. São Paulo: Companhia das Letras, 2000. 